\title{
Synthesis of the Sodalite by Geopolymerization Process Using Coal Fly Ash
}

\author{
Magdalena Król*, Piotr Rożek, Włodzimierz Mozgawa \\ Faculty of Materials Science and Ceramics, AGH University of Science and Technology, \\ 30 Mickiewicza Av., 30-059 Kraków, Poland
}

Received: 31 January 2017

Accepted: 5 April 2017

\begin{abstract}
This study investigated the influence of alkali activation process conditions on the amount and types of zeolites in the resultant geopolymers. The products were formed during the alkaline activation of coal fly ash with the use of aluminium and sodium hydroxide solution. Geopolymers were cured at $80^{\circ} \mathrm{C}$ for $24 \mathrm{~h}$. The effects of reaction systems' constitution (expressed as $\mathrm{SiO}_{2} / \mathrm{Al}_{2} \mathrm{O}_{3}$ and $\mathrm{Al}_{2} \mathrm{O}_{3} / \mathrm{Na}_{2} \mathrm{O}$ molar ratios) on the phase composition and structure of obtained products were determined. The results indicated that the products obtained from such hydrothermal treatment demonstrated the characteristics of zeolite-like materials - sodalite. By using the appropriate composition of the initial solution (sufficiently high concentration of $\mathrm{NaOH}$ and aluminum carrier), it is possible to synthesize the sodalite phase efficiently in an amorphous matrix.
\end{abstract}

Keywords: geopolymers, alkali activation, coal fly ash, sodalite

\section{Introduction}

Geopolymers, also called inorganic polymers, are classified as synthetic aluminosilicate materials characterized by many interesting properties. This group of materials has gained a lot of attention in the past 10 years (measured by increasing number of publications) and raised high expectations concerning their applicability. Geopolymers are usually hard, mechanically resistant materials, therefore many attempts to substitute Portland cement in the construction industry have been taken [1] Despite the huge number of publications devoted to this family and hundreds of new examples of these materials, researching them is still pioneering [2]. Attempts to

*e-mail: mkrol@agh.edu.pl systematize their structures and properties are just beginning to appear.

Geopolymers are considered as zeolite precursors, thus zeolites are often detected in geopolymer gels. Activation of metakaolinite with sodium silicate and sodium hydroxide solutions at various temperatures $\left(20-100^{\circ} \mathrm{C}\right)$ can lead to the geopolymer-zeolite hybrid materials containing zeolite A, sodalite, and zeolite Y [3]. During hydrothermal treatment at low temperature, depending on the synthesis conditions, metakaolin-based geopolymeric gel transforms into zeolite ZSM-20, zeolite Na-P1, faujasite, sodalite, and analcime [4]. Metakaolin-based geopolymeric gel was also used for hydrothermal preparation of a faujasite zeolite membrane for alcohol/water separation [5]. On the other hand, non-hydrothermal preparation of $\mathrm{Na}$-A zeolite membranes from chemosynthetic $\mathrm{Al}_{2} \mathrm{O}_{3}-\mathrm{SiO}_{2}$ powder and sodium silicate solution by the geopolymer gel thermal conversion at $60^{\circ} \mathrm{C}$ is possible [6]. 
Metakaolinite is a relatively expensive raw material. Literature data [7-9] show that the zeolite structures can be synthesized not only in metakaolinite-based material. Actually, zeolites can be synthesized under hydrothermal conditions by heating many other aluminosilicate raw materials such as fly ash [10] or volcanic glasses in the presence of alkaline solutions [11-12]. Resulting zeolites such Na-P1, X, A, and others have a high industrial application potential due to the high cation exchange capacity (CEC) values [10]. However, in laboratory conditions, zeolites can be obtained only by highlydisperse powder.

It is possible to obtain chabazite and sodalite in fly ashbased geopolymers (as monolith) and also zeolite $\mathrm{X}$ and zeolite $4 \mathrm{~A}$ in geopolymers activated with weak alkaline solution and zeolite Na-P1 with a strong activator [7]. Interestingly, the disposal of secondary waste materials such as fly ash (a by-product of coal combustion) has become both an economic and an environmental issue. Fly ash could be utilized as substrate in geopolymerization, as in [8], where geopolymers containing nanocrystalline zeolite phases such as Na-P1 and sodalite from fly ash and slag mixture or $\mathrm{Ca}$-chabazite and faujasite were synthesized by a hydrothermal treatment at $90^{\circ} \mathrm{C}$ without slag addition. Sodalite hydrothermally synthesized from alkali-activated coal fly ash was used for $\mathrm{Pb}^{2+}$ cation adsorption [9].

The above-mentioned literature indicates that alkaliactivation treatment of the aluminosilicate raw material such as coal fly ash can yield to bulk materials with different amounts and types of zeolite and different mechanical properties [13-14]. The geopolymerization gives rise to amorphous or subcrystalline tectoaluminosilicates with structures similar to zeolites. Chemical and mineralogical similarity of geopolymers to natural zeolites [2] should provide very good resistance to high temperature and a chemically aggressive environment. It is assumed that resulting membranes, depending on their phase composition, could be used for the separation of small molecules such as $\mathrm{CO}_{2}$.

In our presented work, an attempt was made to synthesize the zeolite or the zeolite-like phase in the mineral matrix of alkaline-activated coal fly ash. In contrast to the procedures described in the related literature [7, 9], the proposed process was conducted at relatively low temperature and autogenous pressure as well as without thermal pretreatment. Since the composition of fly ash is not suitable for this type of synthesis (too high $\mathrm{Si} / \mathrm{Al}$ molar ratio), it was assumed that the zeolite phase, such as zeolite A, zeolite X, or hydroxysodalite, will be obtained by the addition of an aluminum source.

\section{Experimental}

\section{Materials and Methods}

Coal fly ash collected from electrostatic precipitators of a Polish power plant running on hard coal, was activated with alkaline of sodium hydroxide $(\mathrm{NaOH} ; \mathrm{POCH})$ and sodium aluminate $\left(\mathrm{NaAlO}_{2}, \mathrm{POCH}\right)$ solutions. The geopolymer slurry was molded, sealed, and cured at $80^{\circ} \mathrm{C}$ for $24 \mathrm{~h}$. Finally, samples were dried at room temperature for 28 days. Compositions of prepared materials were collected in Table 1.

The synthetic products were examined by x-ray fluorescence, x-ray diffraction (XRD), and Fourier transform infrared spectroscopy (FT-IR). The specific surface area, pore volume, microstructure (SEM), and compressive strength were also investigated.

\section{Apparatus}

Chemical composition of basic samples was determined using x-ray fluorescence. Spectra were detected with a wavelength-dispersive $\mathrm{X}$-ray fluorescence spectrometer (WD-XRF) Axios mAX 4 kW (PANalytical) equipped with an Rh source. The PANalytical standardless analysis package Omnian was applied for quantitative analysis of the spectra. Particle size of initial coal fly ash was measured using a Mastersizer 2000 analyzer.

The alteration products were identified by means of a Philips X-ray powder diffraction X'Pert system $(\mathrm{CuK} \alpha$ radiation, $40 \mathrm{kV}, 30 \mathrm{~mA}$ ). The measuring time was $4 \mathrm{~h}$

Table 1. The compositions of prepared samples.

\begin{tabular}{|c|c|c|c|c|c|c|}
\hline \multirow{2}{*}{ Sample name } & \multicolumn{2}{|c|}{ Molar ratio } & \multicolumn{4}{c|}{ Reactants } \\
\cline { 2 - 7 } & $\mathrm{Si} / \mathrm{Al}$ & $\mathrm{Al} / \mathrm{Na}$ & $\begin{array}{c}\text { Fly ash } \\
{[\mathrm{g}]}\end{array}$ & $\begin{array}{c}\mathrm{NaOH} \\
{[\mathrm{g}]}\end{array}$ & $\begin{array}{c}\mathrm{NaAlO}_{2} \\
{[\mathrm{~g}]}\end{array}$ & $\begin{array}{c}\mathrm{H}_{2} \mathrm{O} \\
{[\mathrm{ml}]}\end{array}$ \\
\hline A_1:1 & 1.23 & 1.00 & 10.00 & 2.62 & 0.00 & 5 \\
\hline B_1:1 & 1.00 & 1.00 & 10.00 & 3.25 & 1.28 & 5 \\
\hline A_3:2 & 1.23 & 1.50 & 10.00 & 1.71 & 0.00 & 5 \\
\hline B_3:2 & 1.00 & 1.50 & 10.00 & 2.13 & 1.28 & 5 \\
\hline A_2:1 & 1.23 & 2.00 & 10.00 & 1.26 & 0.00 & 5 \\
\hline B_2:1 & 1.00 & 2.00 & 10.00 & 1.57 & 1.28 & 5 \\
\hline
\end{tabular}




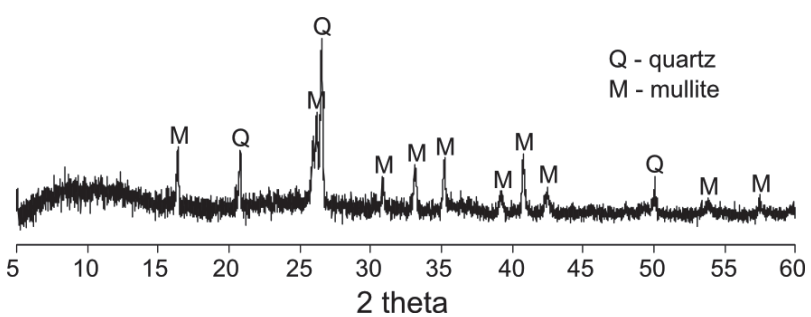

Fig. 1. XRD pattern of initial coal fly ash.

per sample, in the range of 5-90 (20) and step size was 0.008. HighScore software and International Centre for Diffraction Data (ICDD) identification cards were used for data interpretation.

Morphology and crystal size were studied by an FEI Nova NanoSEM 200 scanning electron microscope. The samples were sprayed with graphite. An EDAX attachment was used for elemental analysis at selected points.

Low-temperature nitrogen sorption was performed in the Micromeritics ASAP 2000 device after $24 \mathrm{~h}$ of activation of the studied samples at $400^{\circ} \mathrm{C}$. The specific surface area and pore volume were determined using the BET method.

The existence of zeolite frameworks was confirmed by measurement on a Bruker VERTEX 70v vacuum FT-IR spectrometer using the standard $\mathrm{KBr}$ (Merck) pellets methods. The spectra were collected in $4,000-400 \mathrm{~cm}^{-1}$ range after 128 scans at $4 \mathrm{~cm}^{-1}$ resolution. Precise estimation of the number of bands and their intensity changes is possible after decomposition of the spectra into component bands. Spectra decomposition has been carried out using the Spectra-Calc (Galactic Industries Corp.) program. For all the spectra, the linear baseline correction has been carried out before the decomposition process. Based on the second derivative, the number of bands was estimated.

Compressive strength of prepared bars was measured with a device that works on the principle of a hydraulic press. Compressive strength is defined as the ratio of the sample breaking force $F$ to the area $A$ on which the force acts $\left(R_{c}=F / A\right)$. The apparent density was determined as the quotient of sample mass $m$ and volume $V(d=m / V)$.

\section{Results and Discussion}

\section{Characteristics of Starting Material}

Coal fly ash was collected from electrostatic precipitators of a Polish power plant in which hard coal combustion is realized at $1,350^{\circ} \mathrm{C}$. The majority of coal fly ash particles (about $60 \%$ ) were $<125 \mu \mathrm{m}$ and about $18 \%$ were $<45 \mu \mathrm{m}$; high reactivity can be expected for this particle size [15]. The bulk density was about $0.68 \mathrm{~g} / \mathrm{cm}^{3}$. XRD analysis (Fig. 1) shows that aforementioned fly ash consisted of $64 \%$ aluminosilicate glassy phase, $25 \%$ mullite, $9 \%$ quartz, and $2 \%$ hematite and magnetite (estimated by the Rietveld refinement). The XRF results of analyzed ash (normalized to $100 \%$ ) are presented in Table 2. The Si/Al molar ratio is about 1.23.

Fig. 2 presents the FT-IR spectra on initial fly ash. According to literature [16], the region between

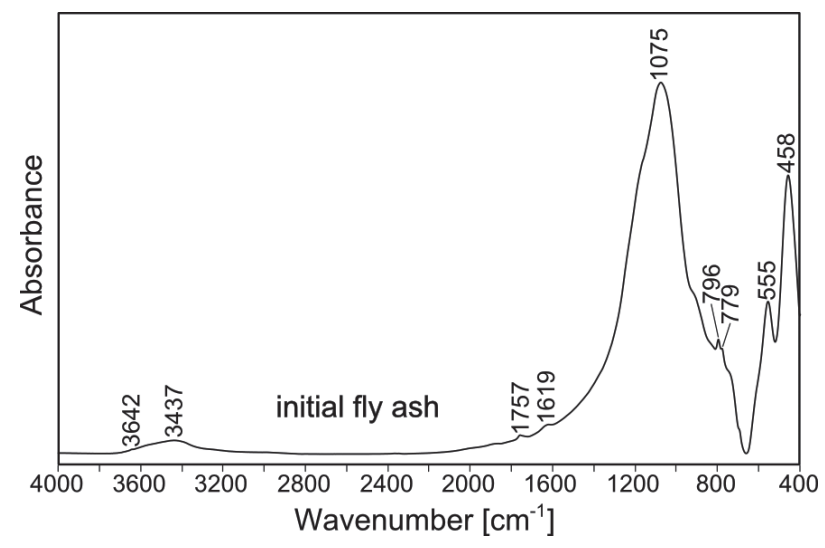

Fig. 2. MIR spectrum of initial coal fly ash.

Table 2. Chemical compositions of initial coal fly ash and resulting geopolymeric samples (wt. \%).

\begin{tabular}{|c|c|c|c|c|c|c|c|}
\hline & \multirow{2}{*}{$\begin{array}{c}\text { Coal } \\
\end{array}$} & \multicolumn{9}{|c|}{ Geopolymeric samples } \\
\cline { 5 - 9 } & & A__1:1 & B_1:1 & A_3:2 & B_3:2 & A_2:1 & B_2:1 \\
\hline $\mathrm{SiO}_{2}$ & 50.58 & 36.81 & 25.46 & 37.78 & 26.23 & 42.27 & 34.26 \\
\hline $\mathrm{TiO}_{2}$ & 1.21 & 1.10 & 1.01 & 1.24 & 0.95 & 1.03 & 1.08 \\
\hline $\mathrm{Al}_{2} \mathrm{O}_{3}$ & 34.94 & 24.14 & 18.32 & 25.30 & 19.52 & 28.99 & 25.00 \\
\hline $\mathrm{Fe}_{2} \mathrm{O}_{3}$ & 3.93 & 3.66 & 4.54 & 4.25 & 3.70 & 3.30 & 4.02 \\
\hline $\mathrm{MgO}$ & 1.26 & 0.90 & 0.80 & 0.84 & 0.59 & 1.01 & 0.76 \\
\hline $\mathrm{CaO}$ & 1.65 & 1.30 & 0.41 & 1.37 & 1.38 & 1.22 & 1.65 \\
\hline $\mathrm{Na}_{2} \mathrm{O}$ & 0.91 & 1.70 & 3.14 & 1.93 & 3.39 & 1.72 & 2.96 \\
\hline $\mathrm{K}_{2} \mathrm{O}$ & 3.02 & 28.98 & 44.28 & 25.77 & 42.44 & 19.09 & 28.03 \\
\hline Others & 2.50 & 1.40 & 2.04 & 1.53 & 1.81 & 1.37 & 2.26 \\
\hline
\end{tabular}




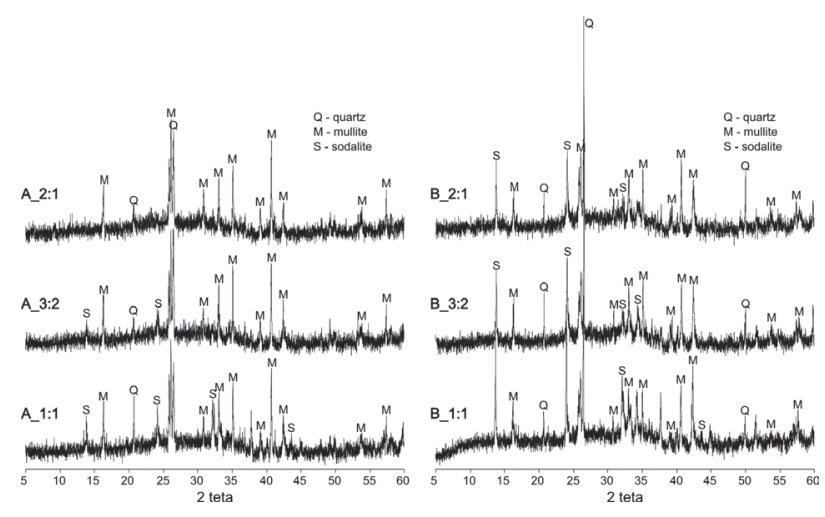

Fig. 3. XRD pattern of fly ash after the geopolymerization process.

1,250 and $950 \mathrm{~cm}^{-1}$ can be attributed to the inner bonds of the tetrahedral asymmetric stretching zone and the asymmetric stretching of external bonds between tetrahedral zones. The maximum located at about 1,075 $\mathrm{cm}^{-1}$ is the superposition of several component bands (among other things) because of the multiphase character
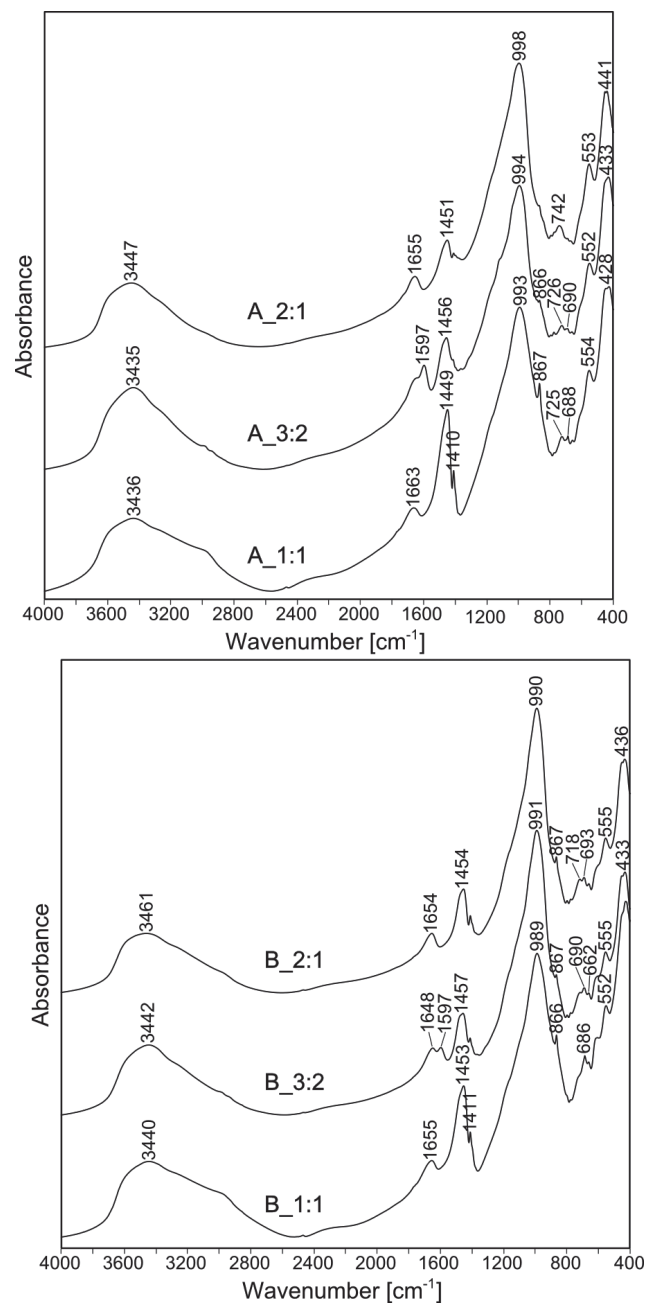

Fig. 4. FT-IR spectra of fly ash after the geopolymarization process. of the sample. The doublet at 796 and $779 \mathrm{~cm}^{-1}$ is a characteristic band of quartz.

\section{The Results of Research and Discussion}

In XRD patterns of the samples after alkaline activation (Fig. 3) correspond to crystalline phases of quartz and mullite as well as an amorphous halo around $29^{\circ}$, which is the result of the N-A-S-H gel formed during hydration. Although hydroxysodalite was identified in the secondary phase, from the point of view of chemical composition of N-A-S-H gel, zeolite A or X can be expected. The formation of sodalite and not zeolites can be explained thermodynamically by higher stability of the denser sodalite lattice. The addition of sodium aluminate (decrease in $\mathrm{Si} / \mathrm{Al}$ ratio; series " $\mathrm{B}$ ") promotes the formation of sodalite. Intensity of the peaks also increased with $\mathrm{NaOH}$ concentration.

Fig. 4 demonstrates the change in fly ash after the geopolymerization process. The chemical composition of both starting material and geopolymerization products give rise to the presence of $\mathrm{Si}-\mathrm{O}$ vibration in the spectral range $1,000-400 \mathrm{~cm}^{-1}$. The most intensive band in this range can be attributed to bridging $\mathrm{Si}-\mathrm{O}(\mathrm{Si}, \mathrm{Al})$ vibrations, which shifts from about $998 \mathrm{~cm}^{-1}$ (for the sample series activated with $\mathrm{NaOH}$; "A" series) to $990 \mathrm{~cm}^{-1}$ (for the samples with sodium aluminate addition; "B" series). Some authors [17] point out that such a shift is an indicator of an increased degree of cross-linking with reactive aluminum content. However, the appearance of the signal at a lower frequency is instead linked with the fact that Al-O bond is longer than $\mathrm{Si}-\mathrm{O}$ and is characterized by smaller bond force constant [18].

The IR spectrum envelop in this range consists of several component bands that can be clearly visible after the decomposition process (Fig. 5). Bands appearing at the highest wavenumbers (at 1,144 $\mathrm{cm}^{-1}$ ) can be assigned to asymmetric stretching vibrations of bonds with bond order higher than one [19]. As mentioned, the main band at $1,056 \mathrm{~cm}^{-1}$ can be connected to internal $\mathrm{Si}-\mathrm{O}(\mathrm{Si}, \mathrm{Al})$ vibrations. Integral intensity of this band decreases with increasing sodium content in the reaction system. At the

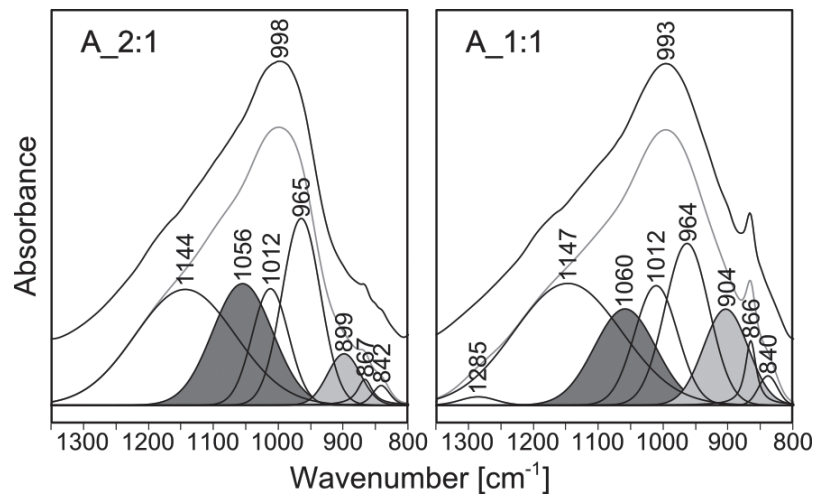

Fig. 5. Decomposition of the FT-IR spectra of the samples: a) A 2:1 and b) A 1:1. 
same time, the intensity of the band at about $900 \mathrm{~cm}^{-1}$ is increased, so this broad overlapping shoulder is probably due to stretching vibrations of terminal $\mathrm{Si}^{-} \mathrm{O}^{-}$bonds. This observation indicates that alkali metals work in such a system as the modifier, resulting in breaking the bridge bond.

The next band in this range of the spectrum, at $1,012 \mathrm{~cm}^{-1}$, can be also assigned to the $\mathrm{Si}-\mathrm{O}(\mathrm{Si})$ bond, however, its low full width at half maximum (FWHM) indicates its crystalline phase origin - in this case probably quartz, which did not participate in the reaction. The presence of the band at $965 \mathrm{~cm}^{-1}$ can be explained as both asymmetric stretching vibrations of $\mathrm{Si}-\mathrm{O}(\mathrm{Al})$ bonds realized in the structures of sodalite and mullite [20], or less likely as Al-OH stretching vibrations of aluminum in the octahedral position [21].

An IR range of $800-500 \mathrm{~cm}^{-1}$ seems to be the most interesting from the point of view of zeolite phases. In this range the bands are observed due to vibrations of overtetrahedral units (so-called ring vibrations) [22]. Bands characteristic for sodalite structure (at 725, 702, and $663 \mathrm{~cm}^{-1}$ ) are in good agreement with related literature [23].

The intense band with high FWHM at about $3,460 \mathrm{~cm}^{-1}$ can be assigned to stretching vibrations of $\mathrm{O}-\mathrm{H}$ bonds. Corresponding bending vibrations are observed at about $1,655 \mathrm{~cm}^{-1}$. This group of bands may be associated with water, which was bonded in an amorphous hydration reaction product, namely $\mathrm{N}-\mathrm{A}-\mathrm{S}-\mathrm{H}$ gel, but also with zeolite water.

Vibrations giving groups of bands at about $1,450 \mathrm{~cm}^{-1}$ are connected with the presence of carbonate groups ( $\mathrm{C}-\mathrm{O}$ bond), as the reaction product of $\mathrm{N}-\mathrm{A}$ $\mathrm{S}-\mathrm{H}$ and partially $\mathrm{NaOH}$ with atmospheric $\mathrm{CO}_{2}$. The carbonates groups are characterized by a doublet band at 1,449 and $1,410 \mathrm{~cm}^{-1}$, and a weak band visible at $866 \mathrm{~cm}^{-1}$. The envelope with several component bands
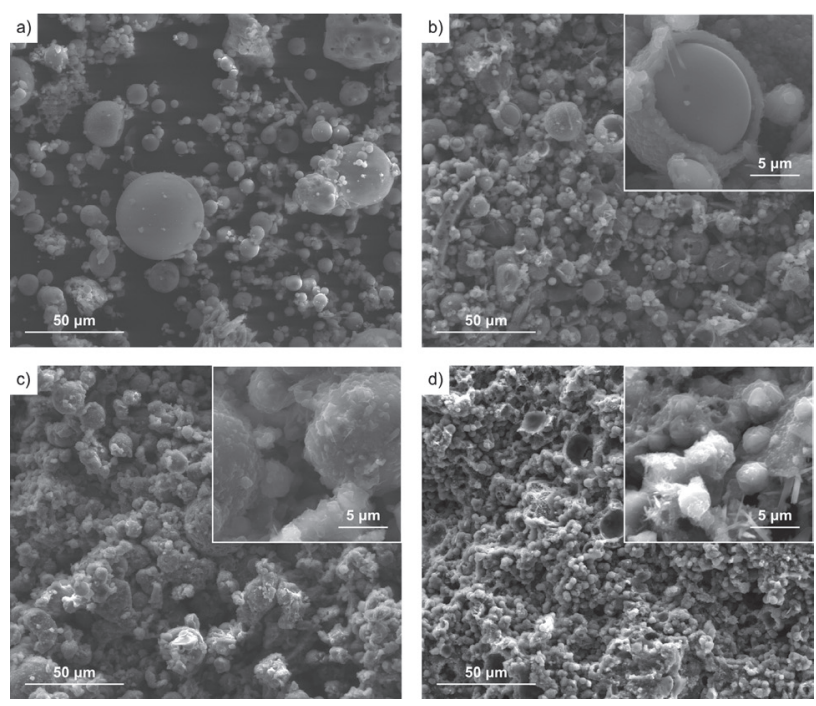

Fig. 6. SEM observations of the samples: a) fly ash, b) A_2:1, c) A_1:1, and d) B_1:1. at higher wave numbers indicates various symmetry of carbonate groups or the presence of other phases, such as hydrated carbonates $\left(\mathrm{Na}_{2} \mathrm{CO}_{3} \mathrm{H}_{2} \mathrm{O}\right)$ [24].

Fig. 6 shows the SEM micrographs of the samples obtained in different conditions. Spherical particles of amorphous phase characteristic for coal fly ash are visible in Fig. 6a). The reaction mechanism of fly ash with the alkaline solution, described inter alia by [25-26], involves dissolution of the amorphous phase and condensation of reaction products inside and outside the shell of the sphere. Not completely consumed fly ash particles with $\mathrm{N}-\mathrm{A}-\mathrm{S}-\mathrm{H}$ gel on the surface are visible in Fig. 6b). Alkali activation of fly ash with the use of a higher $\mathrm{NaOH}$ concentration (lower Al/Na molar ratio; Fig. 6c) results in the formation of larger amounts of amorphous gel, forming the matrix for the residual almost-consumed ash particles. This observation agrees well with related literature [27] regarding increased dissolution of aluminosilicate starting material influencing geopolymerization and subsequently on mechanical properties (compressive strength) of hardened geopolymer (Fig. 7).

As mentioned, many authors consider that the major band shift in the MIR spectra (Fig. 4) is caused by the increased polymerization degree. This thesis can be confirmed by SEM observations of the samples differing in $\mathrm{Si} / \mathrm{Al}$ molar ratio - comparing Fig. 6c) and 6d) it can be concluded that sodium aluminate addition increases the degree of conversion of fly ash and thus the amount of the reaction products.

Carbonation affects mechanical strength adversely [28], therefore the fact of the strength reduction with the addition of sodium hydroxide (decrease of $\mathrm{Al} / \mathrm{Na}$ ratio) in the case of "B" series should not surprise. At the same time, the amount of reaction products (as sodalite) crystallizing in the regular system increases (Fig. 3) and thus shows isometric crystal shape (Fig. 6d), which can also adversely affect the strength parameters. The opposite trend shows the results obtained for the samples from " $\mathrm{A}$ " series. In this case the likely explanation is the increase of reaction products with the alkali activator concentration. It is worth noting that bulk densities of the resulting samples are quite similar and range from 1.30 to $1.45 \mathrm{~g} / \mathrm{cm}^{3}$.

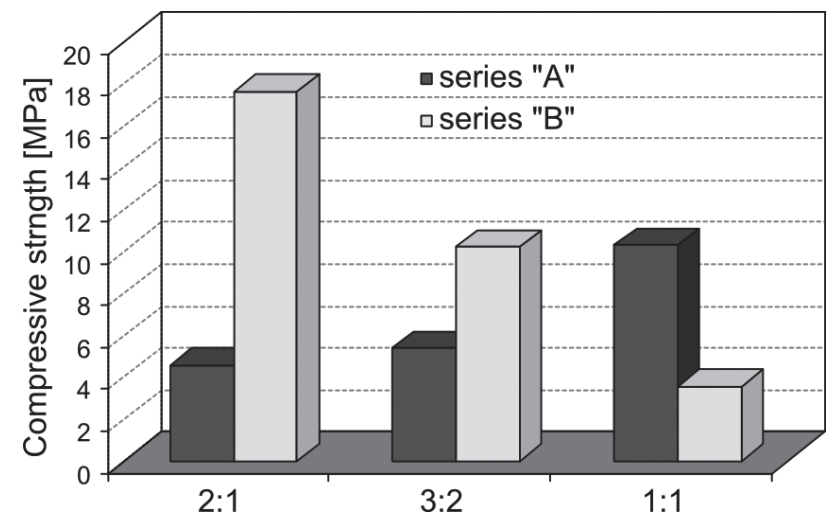

Fig. 7. Compressive strength of fly ash geopolymers. 

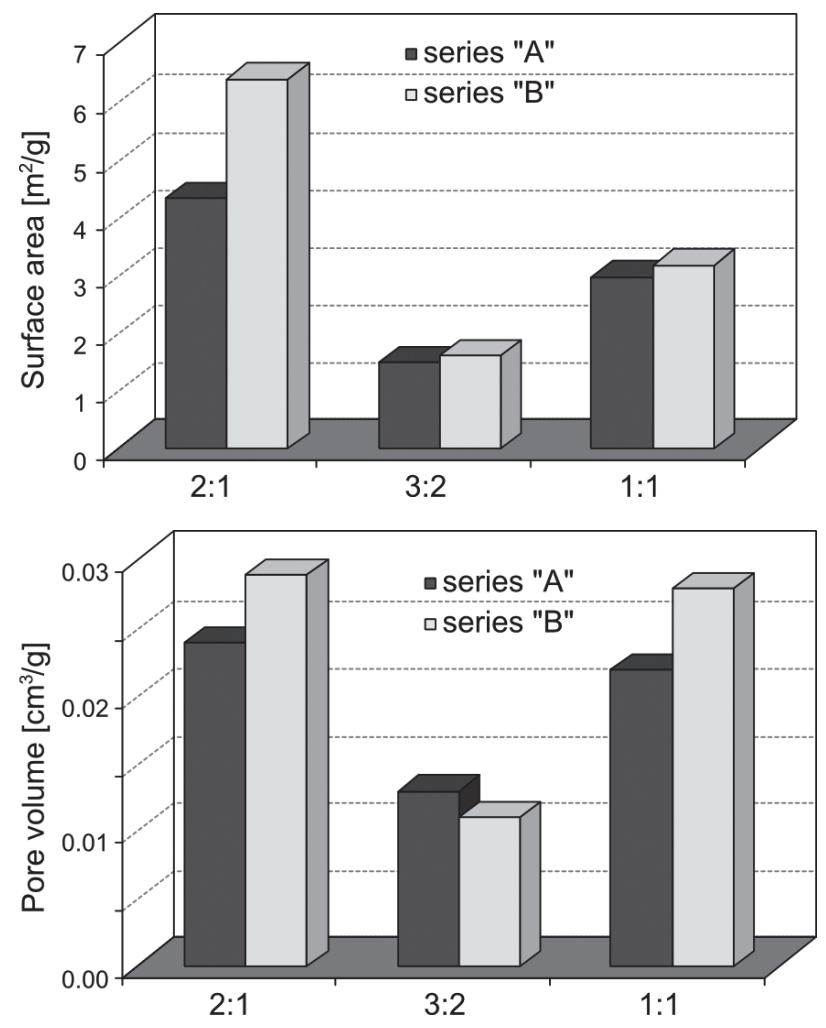

Fig. 8. BET surface area $\left[\mathrm{m}^{2} / \mathrm{g}\right]$ and BJH pore volume of pores between $1.7-300.0 \mathrm{~nm}\left(\mathrm{~cm}^{3} / \mathrm{g}\right)$ of fly ash geopolymers.

The specific surface areas of the samples were determined by BET equation (but also by Langmuir equation not presented here) in the region of relative pressure of $0.06-2.00$ of the adsorption isotherms. Selected derived data are presented in Fig. 8, which illustrates the variation in specific surface area and pore volume with chemical composition of alkali-activated fly ash geopolymers. The value of surface area of resulting materials is in the range of $1.5-6.5 \mathrm{~m}^{2} / \mathrm{g}$. The values of total surface area for pure zeolites are much higher and typically range between $500-800 \mathrm{~m}^{2} / \mathrm{g}$ [29]. This is due to the presence of a substantial amount of amorphous phase in the sample.

For each sample series, the specific surface area depends on the $\mathrm{NaOH}$ concentration (and precisely on the $\mathrm{Al} / \mathrm{Na}$ molar ratio). The surface area values are the result of the degree of fly ash conversion or amorphous phase structure, as well as the presence of sodalite phase. The samples with the lowest $\mathrm{Al} / \mathrm{Na}$ molar ratios are characterized by the highest surface area. This probably corresponds with the presence of some unreacted grain of fly ash, which can be observed during SEM observations (Fig. 6b). The degree of conversion of the ash particle can be also confirmed by MIR spectra analysis (Fig. 5). The decrease in surface area for the " $3: 2$ " samples reflects the crystallization of increasingly compact structures. Consequently, the greatest amount of sodalite is formed at the higher investigated $\mathrm{NaOH}$ concentration (in the " $1: 1$ " samples).
The measurements of the pore distribution, determined on the basis of the BJH equation, suggest that resulting materials are dominated by pores with a diameter of 10-200 nm. Their presence is the result of both intercrystalline pores and structural defects. The high pore volume must have a positive influence on the diffusion processes. The change trend in the mesopore volume is the same as in the case of surface area. It should also be noted that presented results ignore the impact of sodalite phase on the porosity of the material. The presence of zeolite structures cannot be analyzed using the nitrogen absorption method because it is not applicable in the study of micropores in this type of structure [30].

\section{Conclusions}

Using a simple technique, it is possible to synthesize a composite of amorphous material characterized by sufficient compressive strength and crystalline phase with potential good sorption capacity. The change of the reaction system chemical compositions $(\mathrm{Si} / \mathrm{Al}$ and $\mathrm{Al} / \mathrm{Na}$ molar ratios) affects the nature and quantity of obtained crystalline phases. The results suggest the possibility of selecting the optimal composition of starting materials mixture for sodalite synthesis at a relatively low temperature. The presence of sodalite affects the structure, increasing the specific surface area and reducing the mechanical strength of the analyzed composites.

\section{Acknowledgements}

This work was financially supported by the National Science Centre Poland under grant No. 2015/17/B/ ST8/01200.

\section{References}

1. DAVIDOVITS J. Geopolymer Chemistry and Applications. Geopolymer Institute, 2008.

2. DAVIDOVITS J. Geopolymers: Inorganic polymeric new materials. J Therm Anal, 37, 1633, 1991.

3. KRÓL M., MINKIEWICZ J., MOZGAWA W. IR spectroscopy studies of zeolites in geopolymeric materials derived from kaolinite. J Mol Struct, 1126, 200, 2016.

4. TANG Q., HE Y., WANG Y.P., WANG K.T., CUI X.M. Study on synthesis and characterization of ZSM-20 zeolites from metakaolin-based geopolymers. Appl Clay Sci, 129, $102,2016$.

5. ZHANG J., HE Y., WANG Y.P., MAO J., CUI X.M. Synthesis of a self-supporting faujasite zeolite membrane using geopolymer gel for separation of alcohol/water mixture. Mater Lett, 116, 167, 2014.

6. XU M.X., HE Y., WANG Y.P., CUI X.M. Preparation of a non-hydrothermal $\mathrm{NaA}$ zeolite membrane and defect elimination by vacuum-inhalation repair method. Chem Eng Sci, 158, 117, 2017.

7. LEE N.K., KHALID H.R., LEE H.K. Synthesis of mesoporous geopolymers containing zeolite phases by a 
hydrothermal treatment. Microporous Mesoporous Mater, 229, 22, 2016.

8. ÁlVAREZ-AYUSO E., QUEROL X., PLANA F., ALASTUEY A., MORENO N., IZQUIERDO M., FONT O., MORENO T., DIEZ S., VÁZQUEZ E., BARRA M. Environmental, physical and structural characterization of geopolymer matrixes synthesised from coal (co-) combustion fly ashes. J Hazard Mater, 154, 175, 2008.

9. LUO J., ZHANG H., YANG J. Hydrothermal synthesis of sodalite on alkali-activated coal fly ash for removal of lead ions. Procedia Environ Sci, 31, 605, 2016.

10. QUEROL X., MORENO N., UMAÑA J.C., ALASTUERY A., HERNÁNDEZ E., LÓPEZ-SOLER A., PLANA F. Synthesis of zeolites from coal fly ash: an overview. I J Coal Geol, 50, 413, 2002.

11. MAMEDOVA G.A. Hydrothermal synthesis of natrolitetype zeolite in the natural halloysite-obsidian system. Glass Phys Chem, 40, 380, 2014.

12. KRÓL M., MOZGAWA W., MORAWSKA J., PICHÓR W. Spectroscopic investigation of hydrothermally synthesized zeolites from expanded perlite. Microporous Mesoporous Mater, 196, 216, 2014.

13. RATTANASAKA U., CHINDAPRASIRT P. Influence of $\mathrm{NaOH}$ solution on the synthesis of fly ash geopolymer. Miner Eng, 2 (12) 1073, 2009.

14. KOMLJENOVIĆ M., BAŠČAREVIĆ Z., BRADIĆ V. Mechanical and microstructural properties of alkali-activated fly ash geopolymers. J Hazard Mater, 181, 35, 2010.

15. ERDOĞDU K., TÜRKER P. Effects of fly ash particle size on strength of Portland cement fly ash mortars. Cement Concrete Res, 28 (9), 1217, 1998.

16. MOZGAWA W., KRÓL M., DYCZEK J., DEJA J. Investigation of the coal fly ashes using IR spectroscopy. Spectrochim Acta A, 132, 889, 2014.

17. DUXSON P., PROVIS J.L., LUKEY G.C., MALLICOAT S.W., KRIVEN W.M., VAN DEVENTER J.S.J. Understanding the relationship between geopolymer composition, microstructure and mechanical properties. Colloid Surface A, 269, 47, 2005.

18. FERNÁNDEZ-JIMÉNEZ A., PALOMO A. Mid-infrared spectroscopic studies of alkali-activated fly ash structure. Microporous Mesoporous Mater, 86, 207, 2005.
19. SITARZ M. The structure of simple silicate glasses in the light of middle infrared spectroscopy studies. J Non-Cryst Solids 357, 1603, 2011.

20. KRÓL M., MOZGAWA W., MORAWSKA J., PICHÓR W. Spectroscopic investigation of hydrothermally synthesized zeolites from expanded perlite. Microporous Mesoporous Mater, 196, 216, 2014

21. SCOTT F.A., GOLDENSON J., WIBERLEY S.E., BAUER W.H. Infrared spectra of aluminum soaps and soaphydrocarbon gels. J Phys Chem, 58 (1), 61, 1954.

22. MOZGAWA W. The relation between structure and vibrational spectra of natural zeolites. J Mol Struct, 596, 129, 2001.

23. MIKUŁA A., KRÓL M., KOLEŻYŃSKI A. Experimental and theoretical spectroscopic studies of $\mathrm{Ag}$-, $\mathrm{Cd}$ - and $\mathrm{Pb}$ sodalite. J Mol Struct, 1126, 110, 2016.

24. CHERNYSHOVA I.V., PONNURANGAM S., SOMASUNDARAN P. Linking interfacial chemistry of $\mathrm{CO}_{2}$ to surface structures of hydrated metal oxide nanoparticles: hematite. Phys Chem Chem Phys, 15, 6953, 2013.

25. PACHECO-TORGAL F., CASTRO-GOMES J., JALALI S. Alkali-activated binders: a review part I, historical background, terminology, reaction mechanisms and hydration products. J Constr Build Mater, 22, 1305, 2008.

26. ABDULLAH M.M.A., HUSSIN K., BNHUSSAIN M., ISMAIL K.N., IBRAHIM W.M.W. Mechanism and chemical reaction of fly ash geopolymer cement - a review. Int J Pure Appl Sci Technol, 6 (1), 35, 2011.

27. RATTANASAK U., CHINDAPRASIRT P. Influence of $\mathrm{NaOH}$ solution on the synthesis of fly ash geopolymer. Miner Eng, 22, 1073, 2009.

28. NATH S.K., MAITRA S., MUKHERJEE S., KUMAR S. Microstructural and morphological evolution of fly ash based geopolymers. Constr Build Mater, 111 (3), 758, 2016.

29. SATTERFIELD C.N. Heterogeneous catalysis in practice. McGraw-Hill, New York, 1980.

30. RUTHVEN D.M. Charaacterization of zeolites by sorption capacity measurments. In: Verified syntheses of zeolitic materials, Robson H., Editor, Elsavier:, 61, 2011. 